\title{
INVESTIGATION OF THE FEASIBILITY OF MANUFACTURING AGGREGATE BY NUCLEAR METHODS
}

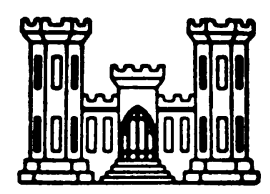

MISCELLANEOUS PAPER NO. 6-643

April 1964

\author{
Sponsored by \\ U. S. ARMY MATERIEL COMMAND \\ Project No. 4A 02260IA880
}

U. S. Army Engineer Waterways Experiment Station CORPS OF ENGINEERS

Vicksburg, Mississippi

ARMY-MRC VICKSBURG, MISS. 